\title{
Leptospirosis: Presentación de una infección fulminante y revisión de la literatura
}

\author{
M. CECILIA ABUAUAD A, GUIDO OSORIO S, \\ JUAN L. ROJAS P y LORENA PINO V.
}

\section{Leptospirosis: Report of a fulminant fatal case and review}

In relation to the explosive increase of new and reemerging infectious diseases that threaten the humanity, and as a result of this clinical case, a literature review is done on Leptospirosis stressing out the necessity of having in mind the leptospirosis in the differential diagnostic for fever and jaundice syndrome .

Key words: Leptospirosis; Jaundice; Fever; Renal failure; Adult Respiratory Distress Syndrome; Panvasculitis.

Palabras clave: Leptospirosis; Ictericia; Fiebre; Falla renal; Síndrome de distrés respiratorio del adulto; Panvasculitis.

\section{Introducción}

La leptospirosis es una enfermedad que debe estar presente en el diagnóstico diferencial de un síndrome febril con ictericia ${ }^{1}$. Es una zoonosis de distribución mundial, en Chile tiene una frecuencia de 400 casos al año ${ }^{2,3}$ y en E.U.A se notifican 100 a 200 casos por año ${ }^{4}$.

Esta afección es causada por espiroquetas del género Leptospira en el cual se han identificado 300 serotipos que infectan a mamíferos salvajes y domésticos ${ }^{4}$.

La infección humana es incidental, ya sea por contacto directo (más raro) o indirecto, a través de suelo o aguas contaminadas ${ }^{5,6}$. En todo el mundo la fuente más común de infección humana es la rata y su mayor frecuencia está en verano y otoño.

El control epidemiológico es difícil puesto que la leptospira persiste por largos periodos en los túbulos renales del hospedero (con bacteriuria), sin causarle enfermedad y los animales salvajes representan un reservorio de infección continua para los animales domésticos ${ }^{7,8}$.
Se presenta a continuación un caso de leptospirosis fetal que fue sospechado clínicamente y confirmado a través de la autopsia y su estudio histopatológico con tinciones especiales.

\section{Caso clínico}

Varón de 16 años, residente de Chimbarongo, VI Región. Tenía como antecedentes padecer de una epilepsia, en tratamiento con fenobarbital. Ingresó a la UCI del Hospital Barros Luco Trudeau (HBLT) el día cuarto de evolución con una historia de tos, expectoración hemoptoica, apremio respiratorio y epistaxis anterior. $\mathrm{La}$ anamnesis describía los primeros días un cuadro caracterizado por fiebre, compromiso del estado general, mialgia, cefalea, vómitos y compromiso de conciencia. Al segundo día de enfermedad se había agregado ictericia intensa, coluria y dolor abdominal. Consultó inicialmente en la Unidad de Emergencia del Hospital de Chimbarongo, siendo referido con el diagnóstico de hepatitis aguda al Hospital de San Fernando, en estado de hipotensión

Hospital Barros Luco Trudeau, Santiago, Chile

Servicio de Gastroenterología (MCAA)

Servicio de Medicina (GOS, LPV)

Universidad de Santiago, Santiago, Chile

Unidad de Anatomía Patológica (JLRP)

Recibido: 1 julio 2004

Aceptado: 20 diciembre 2004 


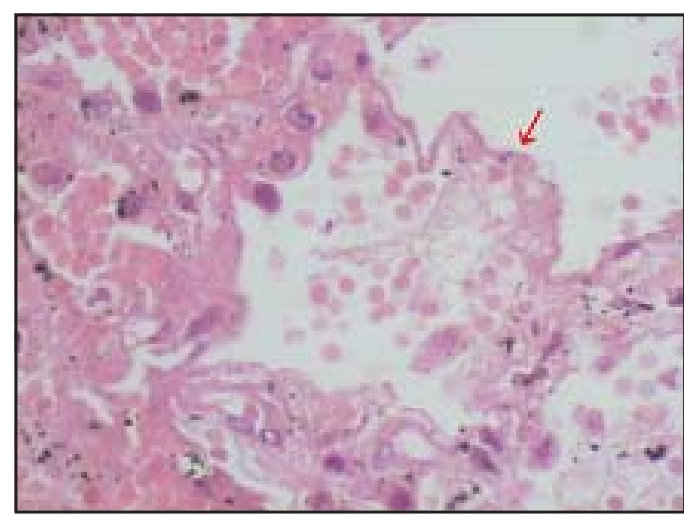

A

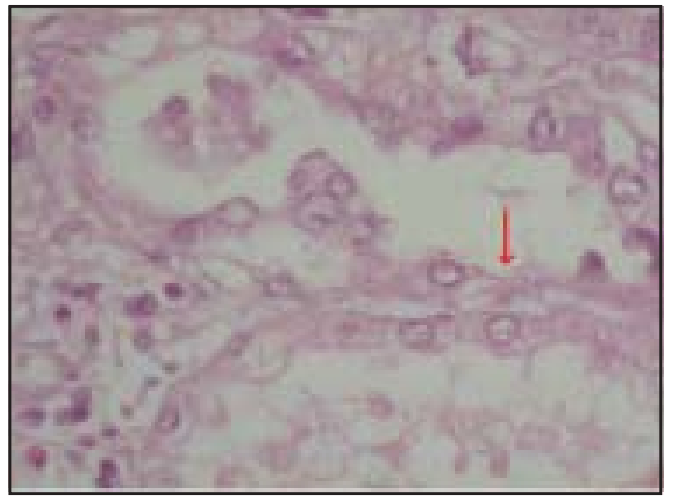

B

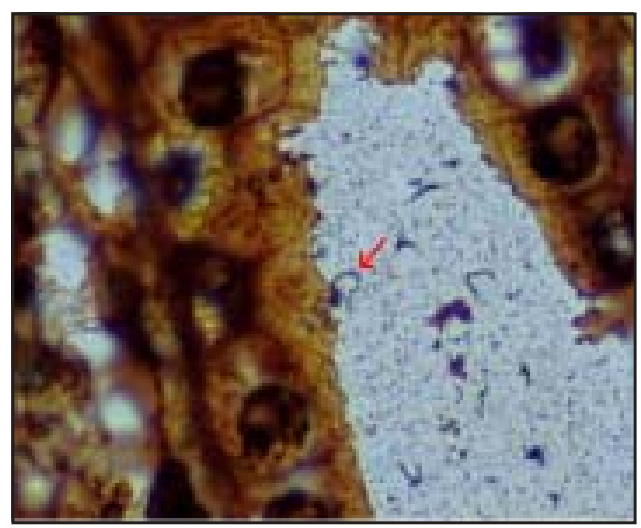

C

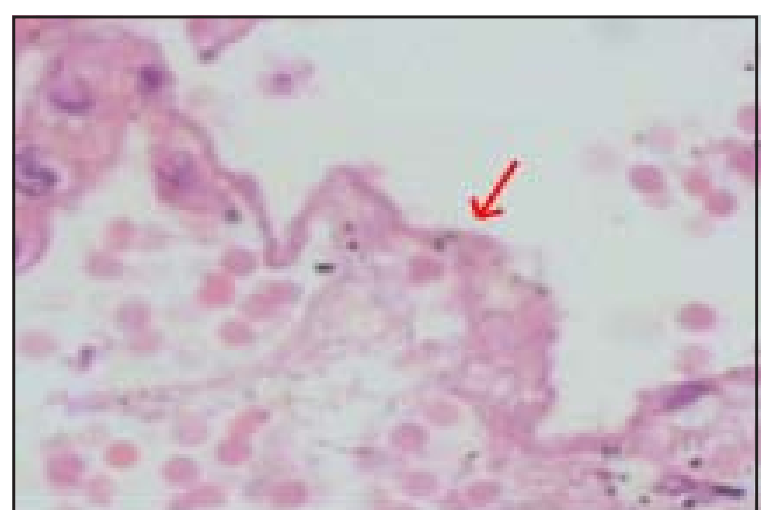

A 1

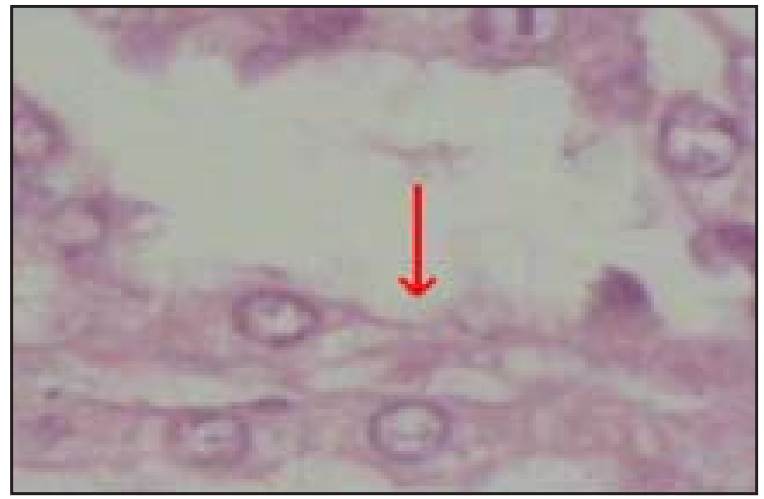

B 1

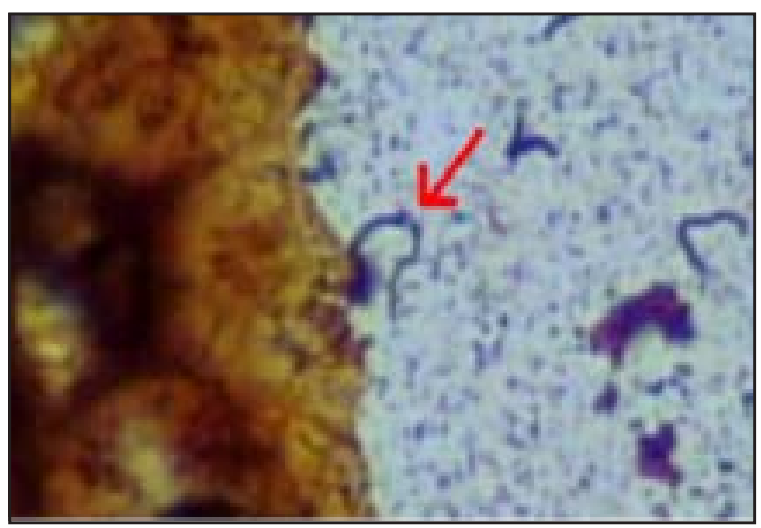

C 1

Figura 1. A: Alveolitis necrosante, tinción de H+E 40X (A1: Detalle)

B: Necrosis tubular aguda, tinción de H+E 40x (B1: La flecha señala necrosis de célula tubular) C: Túbulo renal con leptospira adosada a la superficie epitelial, tinción de Warthin-Starry 100x. (C1: la flecha señala una espiroqueta adosada al epitelio) 
arterial, taquicárdico, con epistaxis y dolor abdominal en el hipocondrio derecho; allí fue asistido con infusión de solución salina al 9\% y dopamina y finalmente enviado al HBLT donde ingresó vigil, orientado en tiempo y espacio, cooperando. Al examen físico destacaban intensa ictericia de piel y escleras, taquicardia, taquipnea, normotensión y fiebre $\left(38^{\circ} \mathrm{C}\right.$ axilar), murmullo pulmonar disminuido en el hemicampo inferior izquierdo y presente en el derecho. Aproximadamente 50 minutos más tarde se describió en estado de shock séptico, debiendo ser intubado, maniobra durante la cual eliminó sangre rutilante por la vía aérea, y fue trasladado a UCI. De allí en adelante evolucionó con escasa respiración espontánea debió ser asistido manualmente, presentaba sangramiento por el tubo orotraqueal, ictericia e isocoria reactiva. Se conectó a ventilación mecánica por una desaturación de $65 \%$, mientras estaba taquicárdico pero con normotensión. Fue ingresado con los diagnósticos de: shock séptico, síndrome de distrés respiratorio del adulto y la hipótesis de una leptospirosis. Evolucionó con PA $0 / 0 \mathrm{~mm} / \mathrm{Hg}$ y falleció a la hora de haber ingresado en UCI, pese a maniobras de reanimación avanzada.

\section{Anatomía patológica}

Los hallazgos morfológicos están relacionados con alteraciones de la microcirculación, caracterizadas por una panvasculitis venulocapilar en todos los órganos y sistemas?.

En el pulmón se apreciaban macroscópicamente extensas áreas de hemorragia parenquimatosa y a la microscopia necrosis alveolar (Figura $1 \mathrm{~A})$.

En el parénquima hepático se observaban extensas áreas de necrosis hepatocelular e infiltrado inflamatorio linfoplasmocitario portal.

El miocardio exhibía degeneración miofibrilar focal y extenso infiltrado linfoplasmocitario intersticial.

El parénquima renal presentaba congestión vascular, vasculitis linfoplasmocitaria y extensa necrosis tubular aguda (Figura 1B). Con la coloración argéntica de Warthin-Starry se identificaron formaciones espirilares adosadas al epitelio tubular en forma de coma, características de leptospira (Figura 1C). Por métodos morfométricos se estableció una longitud promedio de $13 \mathrm{~m} \mu$.

\section{Diagnósticos anátomo-patológicos:}

- Enfermedad de Weil (leptospirosis) con:
- Hemorragia pulmonar parenquimatosaalveolitis necrosante.

- Panvasculitis vénulo-capilar.

- Necrosis tubular aguda-nefritis intersticial linfo-plasmocitaria.

- Hepatitis aguda.

- Miocarditis y pericarditis linfo-plasmocitaria.

- Meningitis linfo-plasmocitaria.

\section{Discusión}

La patogenia de la infección se caracteriza por la penetración de la leptospira a través de las mucosas y paso al torrente circulatorio distribuyéndose hacia todo el organismo ${ }^{10,11}$. En este caso el paciente había tenido, estando en estado de ebriedad, contacto con aguas o suelos probablemente contaminados con leptospira (vivía en un ambiente rural y era verano), donde seguramente contrajo la infección. Presentó un cuadro séptico inicial con rápida aparición de coluria e ictericia. Luego de esto desarrolló una falla hepática aguda, distrés respiratorio con hemoptisis, insuficiencia renal aguda, shock séptico y coagulación intravascular diseminada (CID) que lo condujeron a la muerte. La cefalea relatada podría ser atribuida a una invasión e inflamación cerebral y meníngea que no fuera objetivada ${ }^{10,12}$. El compromiso hepático observado se debió a daño hepatocelular y subcelular con disfunción de su capacidad global de síntesis, lo que se tradujo en un aumento considerable de la bilirrubinemia (hasta $23,7 \mathrm{mg} / \mathrm{dl}$ ) y de las enzimas GGT y fosfatasas alcalinas. Concomitantemente se produjo daño renal con necrosis tubular aguda (atribuible a efecto tóxico directo y/o por inmunocomplejos) $)^{13,14}$, apareciendo posteriormente el evento más grave de distrés respiratorio agudo ${ }^{15,16}$ con hemoptisis y vasculitis extensa generalizada, asociada a CID, shock séptico y muerte ${ }^{9}$.

Esta afección consiste en una infección e inflamación de los parénquimas nobles (cerebro, hígado, riñón, pulmón y a veces el corazón), músculos esqueléticos con rabdomiolisis, dermis y además, una extensa y severa panvasculitis que complica el cuadro clínico, y a cuya aparición se atribuye la alta letalidad de la enfermedad ${ }^{17,18}$. La leptospira puede estar presente también en el humor acuoso originando una uveítis crónica, donde logra persistir por largo tiempo.

La leptospirosis tiene dos formas de presentación clínica: anictérica (90\%) y la forma icterohemorrágica o enfermedad de Weil (10\%), pudiendo haber estados intermedios de la enferme$\operatorname{dad}^{17,19}$. 
Una vez que la bacteria atraviesa desde la mucosa al torrente circulatorio, se produce generalmente un síndrome séptico febril con cefalea, mialgia, compromiso general, dolor abdominal, vómitos e infección conjuntival, manifestaciones que duran 3 a 7 días; en esta etapa se puede aislar leptospira a partir de la sangre y del $\mathrm{LCR}^{12,19}$. Luego se desarrolla el período de respuesta inmune que se extiende por hasta un mes, durante el cual aparecen meningitis, uveítis, fiebre, ictericia, insuficiencias hepática y renal agudas, miocarditis, hemorragia y vasculitis en los casos icterohemorrágicos ${ }^{10,18}$.

En la forma anictérica destacan el síndrome séptico inicial, fiebre, cefalea intensa y a veces, un síndrome meníngeo. La fiebre cede después de diez días, puede haber síndrome de distrés respiratorio leve y también hepatoesplenomegalia ${ }^{10,11}$.

El síndrome de Weil o forma icterohemorrágica, producida por la variedad Leptospira icterohemorragie, se caracteriza por su gravedad y alta letalidad (5 a 20\%); se presentan falla multiorgánica, colapso cardiovascular, shock séptico, CID, vasculitis, hemorragia pulmonar y muerte, como se vivió en este caso clínico ${ }^{9,14}$. Puede presentarse insuficiencia renal aguda con necrosis tubular y que a veces requiere de hemodiálisis -esta paciente falleció antes de manifestarla- y coagulopatía de forma trombopénica como sí ocurrió en este caso. Además compromiso hepático sin gran disfunción hepatocelular según muestra el perfil hepático (GOT bajo de 200 UT, fosfatasa alcalina y GGT aumentadas por el componente colostásico y aumento de la bilirrubina hasta $23,7 \mathrm{mg} / \mathrm{dl}$ ). La CK elevada, producto de la rabdomiolisis, (estuvo aumentada en este caso) permite el diagnóstico diferencial con otras hepatitis agudas ${ }^{10,11,17}$.

Los cultivos bacteriológicos efectuados durante los primeros diez días permiten aislar leptospiras de sangre y LCR, para ello se requieren métodos de cultivo especiales (Fletcher, EMJH y Twean); puede obtenerse leptospiras de biopsias de músculo por ejemplo, y hay buenos rendimientos en la pesquisa bacteriológica usando broncoscopios y lavado bronquioalveolar ${ }^{10,11,19}$. La microscopia de fondo oscuro se usa en el examen de LCR, ayudado por RPC para aumentar su sensibilidad.

La serología utiliza reacciones de aglutinación de antígenos muertos y vivos en portaobjetos o pruebas de hemaglutinación. Hoy es más útil el método de ELISA (de puntos e inmunoblott) que detecta IgM específica desde el sexto día de enfermedad y la elevación de títulos a las 3 semanas, pudiendo persistir positiva por varios meses en títulos bajos. Se describen falsos negativos por el uso previo de antimicrobianos o por tratarse de un serotipo no incluido en el kit diagnóstico. La serología es más sensible y práctica que el cultivo ${ }^{20,22}$.

El tratamiento etiológico de la leptospirosis se efectúa, en las formas severas, con bencilpenicilina G 2 millones $U$ cada 6 horas por vía endovenosa o ampicilina 500 a $1.000 \mathrm{mg}$ cada 6 horas ev; en las formas leves, con doxicilina 100 mg cada 12 horas oral, ampicilina 500 a $700 \mathrm{mg}$ cada 6 horas oral y amoxicilina $500 \mathrm{mg}$ cada 6 horas. El tratamiento debe mantenerse durante 7 días o más, según la evolución clínica ${ }^{4,10,17}$. El uso de corticoesteroides endovenosos en la falla respiratoria secundaria a la respuesta inflamatoria ha sido exitoso.

\section{Comentario final}

La leptospirosis ha emergido como una enfermedad infecciosa, entre tantas que hoy afectan al hombre. Tiene una incidencia creciente y es subdiagnosticada dentro de los síndromes febriles, sépticos e ictéricos de otras etiologías. Siendo una patología que tratada oportunamente favorece la evolución del paciente, creemos que debe contemplarse en el diagnóstico diferencial de síndromes sépticos con ictericia.

\section{Resumen}

Entre las nuevas y re-emergentes enfermedades infecciosas que amenazan a la humanidad, y como resultado de este caso clínico, se hace una revisión bibliográfica acerca de leptospirosis insistiendo en la necesidad de tenerla in mente en el diagnóstico diferencial de un cuadro febril con ictericia.

\section{Bibliografía}

1.- Anales del Seminario Nacional de Zoonosis y Enfermedades de Transmisión Alimentaria. Ministerio de Salud/OPS/CONCYTEC - Lima 1989.

2.- Navarrete Muñoz G. Subsecretario de Salud. "Vigilancia de Leptospirosis" Gobierno de Chile, Ministerio de Salud, Instituto de Salud Publica División Salud Ambiental División Salud de las Personas Depto. Epidemiología $\mathrm{N}^{\circ} 033$. Circular $\mathrm{N}^{\circ} 4 \mathrm{f} / 03$. Santiago, 12 de Febrero de 2002.

3.- Arias H, Núñez M, Valenzuela I, Olivares A. Brote epidémico de leptospirosis en niños de Linares. Rev Chil Pediatr 2003; 74: 405-10.

4.- Vinetz J M. Leptospirosis, Curr Opin Infect Dis 2001; 14: $527-38$

5.- Lomar A V, Veronesi R, de Brito T, Diament D. Leptospiroses. En Veronesi R, Focaccia R, editores. 
Tratado de Infectología. Ed. Atheneu. 1997: 987-1003.

6.- Control de las Enfermedades Transmisibles en el Hombre. Decimosexta edición OPS/OMS -1997 Washington DC.

7.- Zoonosis y Enfermedades Transmisibles Comunes al Hombre y a los Animales. segunda edición 1986 Dr. Pedro N. ACHA - OPS/OMS; Dr. Boris SZYFRES OPS/OMS.

8.- Zamora J, Riedemann S, Frias M. Leptospirosis porcina. Primer aislamiento en Chile de Leptospira interrogans serovar tarassovi. J Vet Med B 1988; 35: $105-8$.

9.- Garrido R, Castillo L, Hernández G, Abarca J, Montes J M, Monsalve V, et al. Systemic leptospirosis as a cause of multiple organ failure. Report of a case. Rev Méd Chile 1996; 124: 359-62

10.- Farr R W. Leptospirosis. Clin Infect Dis 1995; 21: 16 ; quiz 7-8.

11.- Guidugli F, Castro A A, Atallah A N. Systematic reviews on leptospirosis. Rev Inst Med Trop S Paulo 2000; 42: 47-9.

12.- Panicker J N, Mammachan R, Jayakumar R V. Primary neuroleptospirosis. Postgrad Med J 2001; 77: 589-90.

13.- Yang C W, Wu M S, Pan M J. Leptospirosis renal disease, Nephrol Dial Transplant 2001; 16 Suppl 5: 73-7.

14.- Abdulkader R, Daher E F, Camargo E D, Spinosa C, da
Silva M V. Leptospirosis severity may be associated with the intensity of humoral immune response. Rev Inst Med Trop S Paulo 2002; 44: 79-83.

15.- Bethlem E P, Carvalho C R. Pulmonary leptospirosis, Curr Opin Pulm Med 2000; 6: 436-41.

16.- Sanchez Rubio P. Care of a patient with leptospirosis icterohemorragiae. Enferm Intensiva 2000; 11: 1722.

17.- Lomar A V, Diament D, Torres J R. Leptospirosis in Latin America. Emerging and re-emerging diseases in Latin America. Infect Dis Clin North Am 2000: 14; 23-38.

18.- Binder W D, Mermel LA. Leptospirosis in an urban setting: case report and review of an emerging infectious disease. J Emerg Med 1998; 16: 851-6.

19.- Pumarola Suñé T, Jiménez de Anta Losada M T. Leptospirosis. Medicine 2002; 8 (69): 3688-92.

20.- Yersin C, Bovet P, Smits H L, Perolat P. Field evaluation of a one-step dipstick assay for the diagnosis of human leptospirosis in the Seychelles. Trop Med \& Intern Health 1999; 4: 38-45.

21.- Smits H L, Hartskeerl R A, Terpstra W J. International multi-centre evaluation of a dipstick assay for human leptospirosis. Trop Med \& Internat Health 2000; 5: 124-8.

22.- Manual de Leptospirose, Ministerio Da Saude, Fundacao Nacional de Saude - Brasilia 1997.

Correspondencia a:

M. Cecilia Abuauad Abo-mohor

jorilola@msn.com 